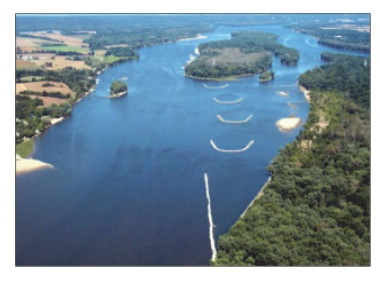

\title{
USACE Regional Sediment Management and Engineering With Nature 2012 Workshop Summary
}

\author{
By Cynthia J. Banks and Jennifer M. Gerhardt Smith
}

PURPOSE: This document summarizes the major findings of a workshop entitled "Regional Sediment Management (RSM) and Engineering With Nature (EWN)." The workshop was held August 28-30, 2012, at the U.S. Army Engineer District, Portland, in Portland, Oregon. The goals of the workshop were to introduce the EWN initiative; identify opportunities and establish collaborations between RSM and EWN; and conduct the annual RSM In-Progress-Review. The workshop was sponsored by the U.S. Army Corps of Engineers (USACE or the Corps) Engineer Research and Development Center (ERDC) RSM and Dredging Operations Environmental Research (DOER) Programs and further served as a conduit to share technical presentations and lessons learned. The workshop also provided a venue for participants to network, to participate in valuable discussions of relevant experiences, and to generate outcomes that will support the USACE Navigation, Flood Risk Management, and Environmental Restoration missions. Coordinators of the workshop were Linda Lillycrop of the ERDC Coastal and Hydraulics Laboratory and Dr. Todd Bridges of the ERDC Environmental Laboratory.

\section{OVERVIEW OF RSM AND EWN:}

Regional Sediment Management. RSM is a systems-based approach implemented collaboratively with other federal, state, and local agencies. The purpose of the program is to adjust our focus from managing projects and sediments on local scales to regional scales. Realizing this goal will provide opportunities to implement adaptive management strategies across multiple projects, which will allow us to optimize the use of sediments while supporting sustainable solutions to the USACE Navigation, Flood and Storm Damage Reduction, and Environmental Restoration missions. While RSM strategies increase benefits, an additional goal is to reduce costs or collaborate with partners to share costs.

The RSM Program provides opportunities to evaluate and implement various RSM actions throughout USACE districts as pilot projects, with the objectives of improving sediment management practices and strategies in the short-term and providing lessons learned that will later benefit other districts and regions. The pilot projects have resulted in the advancement of technologies and communications that have positioned the USACE to more efficiently and effectively implement regional approaches to improve our understanding of regional processes. The advancement of technology and communications have also led to more opportunities to share information and data, collaborate with stakeholders and partners, improve decision making, implement strategies that improve the management of sediments, and link multiple projects.

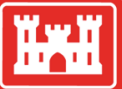

US Army Corps of Engineers ${ }_{\circledast}$ and social benefits through collaborative processes.

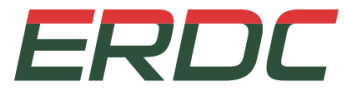

Engineer Research and Development Center 
July 2014

Engineering With Nature. Sustainable development of water resources infrastructure is supported by solutions that beneficially integrate engineering and natural systems. With recent advances in the fields of engineering and ecology, there is an opportunity to combine these fields of practice into a single collaborative and cost-effective approach for infrastructure development and environmental management.

EWN is a USACE initiative to enable more sustainable delivery of economic, social, and environmental benefits associated with water resources infrastructure. EWN directly supports USACE's “Sustainable Solutions to America's Water Resources Needs: Civil Works Strategic Plan 2011-2015" and contributes to the achievement of its Civil Works Mission and Goals.

EWN is defined as the intentional alignment of natural and engineering processes to efficiently and sustainably deliver economic, environmental, and social benefits through collaborative processes.

EWN is about creating new ways of conducting business and expanding the benefits of USACE infrastructure projects through effective partner and stakeholder collaboration.

The essential ingredients of EWN are to:

- use science and engineering to produce operational efficiencies supporting sustainable delivery of project benefits;

- use natural processes to provide maximum benefit; thereby reducing demands on limited resources, minimizing the environmental footprint of projects, and enhancing the quality of project benefits;

- broaden and extend the base of benefits provided by projects to include substantiated economic, social, and environmental benefits; and

- use science-based collaborative processes to organize and focus interests, stakeholders, and partners to reduce social friction, resistance, and project delays while producing more broadly acceptable projects.

Figure 1 shows an aerial photo of river training structures known as chevrons along the Mississippi River. These structures demonstrate cost-effective engineering practices; the structures also support navigation and enhance habitat value for a number of species. Advancing the use of EWN within current and future practice will be pursued through innovative demonstrations, clear communications about lessons learned, focused research and development, and active engagement and collaboration with partners and stakeholders.

WORKSHOP OVERVIEW: The 60 participants in the workshop included representatives from USACE Headquarters (HQ), 21 USACE districts, scientists, and engineers from ERDC, as well as representatives from academia and industry. The workshop included numerous technical presentations and group breakout sessions on a broad range of issues and topics, including innovative engineering and operational practices, numerical modeling, and strategic communications for the advancement of a joint RSM and EWN community. The workshop also included the annual RSM In-Progress-Review to share progress, status, and lessons learned from ongoing RSM initiatives, and to identify opportunities to incorporate EWN concepts. 


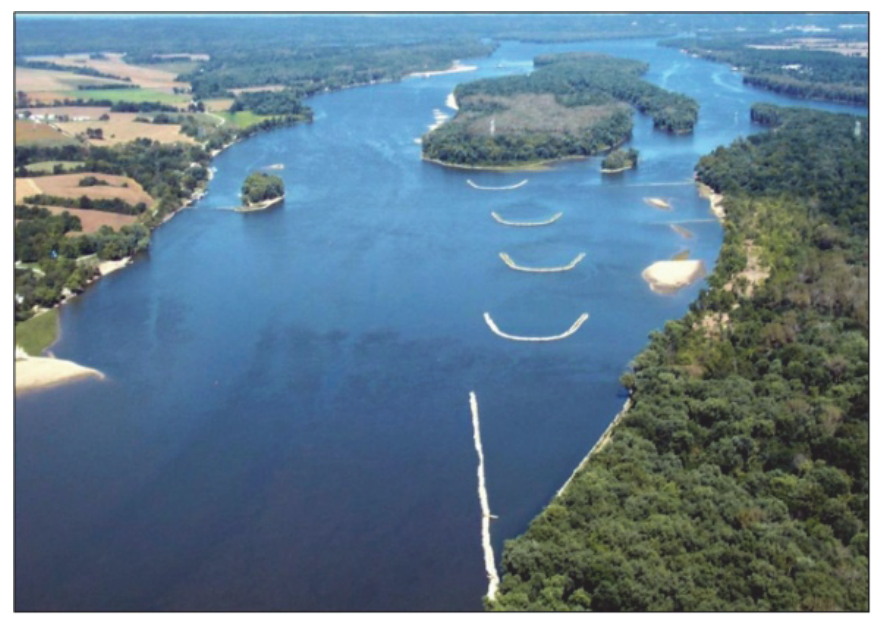

Figure 1. Aerial view of river engineering structures (Photo courtesy of USACE St. Louis District).

The workshop began with the USACE Navigation Business Line Manager briefing. This briefing provided the USACE HQ perspective on the effort to move forward with RSM and EWN across the USACE. This was followed by a series of presentations to help build a shared understanding of the context and opportunity for applying EWN within the Civil Works missions. Representatives from the ERDC Coastal and Hydraulics Laboratory (CHL) and Environmental Laboratory (EL); USACE districts, including Mobile and Galveston; and academia discussed opportunities for past and ongoing projects related to EWN.

Building on the presentations and discussion that followed, participants were divided into six facilitated breakout groups and asked to complete three specific questions (one question per day) related to opportunities, gaps, and communications. Each group was asked the following questions:

1) What are the biggest opportunities for advancing RSM and EWN within USACE missions? What actions can Operations and Maintenance (O\&M) project delivery teams (PDTs) take to incorporate RSM and EWN approaches within their projects?

2) What gaps in science, technology, engineering, or organizational practice should be addressed to advance RSM and EWN across Corps mission areas? What gaps are particular to the Navigation O\&M Program?

3) How should we be communicating and collaborating with others to take advantage of RSM and EWN opportunities?

After eliciting responses, along with the rationale behind each response, the group discussed and defined its top priorities. The groups briefly ( 5 minutes) reported back to the plenary session at the end of each day. The information presented below summarizes participant input during breakout group discussions. 
July 2014

\section{SUMMARY OF BREAKOUT GROUP DISCUSSIONS:}

\section{Question 1}

What are the biggest opportunities for advancing RSM and EWN within USACE missions?

1. Navigation

2. Flood and Coastal Storm Damage Reduction

3. Environment

4. Hydropower

5. Regulatory

6. Recreation

7. Emergency Management

8. Water Supply

9. Support for Others

10. Military Programs

What actions can O\&M PDTs take to incorporate RSM and EWN approaches within their projects?

Policy

- Permitting

- Streamline regulatory permits for EWN and RSM activities to encourage incorporation of those approaches by permit applicants.

- Greater opportunity could be realized if the permitting processes were more conducive to systems approaches.

- Funding

- Increase value to the nation through changes to the Corps' funding structure; changes would provide for more flexible allocation of funds across missions, business lines, assets, and projects.

- Improve cost-sharing mechanisms to leverage funding and encouraging multiple cost-sharing partners.

- Make EWN and RSM funding programmatic and competitive across the Corps.

O Water supply needs its own funding and dedicated authority.

- Contracting

$\circ$ The Corps contracting mechanism needs to gain flexibility for pooling funds across business lines for increased benefits.

- Include EWN in performance-based criteria.

- Support

○ Headquarters-level policy support (such as mention of RSM and EWN in Campaign Plans or the like) would help push the initiatives farther forward.

- Division and district-level commander official support would help solidify RSM's and EWN's place in project execution and program development. 
Process

- Benefit Calculation

○ Consider long-term, down-drift, and secondary and tertiary benefits, as opposed to "without-project conditions" in calculations.

- Account for the negative impacts of removing sediment from sediment-starved systems when placing material for disposal upland or in an ocean. Give same considerations to ocean disposal sites (ODS).

- Planning Documents

- Include RSM and EWN in Dredged Material Management Plan (DMMP) formulation and annual review.

- Highlight RSM and EWN in environmental documentation such as feasibility studies, Environmental Assessments.

- Project Planning

○ Consider breaking from standard PDT.

O Fully utilize interdisciplinary knowledge; include regulatory and ERDC personnel.

- Consider using the regional and systems approaches; combine projects.

- Include added design time in schedule for EWN measures/features.

Communication, Coordination, Collaboration

- Communication

- Develop a standard procedure to transfer data to resource agencies to maximize their exposure to information, build trust, and secure buy-in.

- Promote EWN in environmentally conscientious areas to reduce conflict.

- Create a robust and consistent strategy for communication internally and externally.

- Develop RSM and EWN advocacy teams.

- Communicate with as broad a suite of stakeholders as early as possible.

○ Hold "no-decision," information-only meetings. Identify assumptions and needed data.

- Coordination and Collaboration

- Increase cross-purpose initiatives with Military Programs, Flood and Storm Damage Reduction, Recreation.

- Use annual DMMP review and other annual events to hold Charrette-style meetings for collaboration before each major stage of project planning.

- Be active, ask stakeholders for in-kind services such as monitoring and planting.

Tools and Technology

- Science

○ Use technology to develop sediment deficiency status reports for supporting sediment "re-introduction."

○ Improve real-time monitoring of dredged material quality.

- Innovations

○ Develop better technology to aid acceptance of fine-grained sediments. 
- Use decision-making tools (such as D2M2) to increase understanding and create cooperative agreements with stakeholders.

$\circ$ Engineer solutions to remove sediments with vegetation.

- Cultivate Corps data-sharing to be more open, accessible, and compatible.

Project Measures and Features

- Reservoirs

O Enhance sediment management guidance with RSM and EWN in mind.

$\circ$ Engineer solutions to keep sediment moving past dams, such as a retrofit for pulse flows.

- Evaluate deconstruction of dams.

- Other

O Utilize non-dredging options for restoring capacity (hydraulic processes).

- Place in nearshore, submerged areas instead of directly on beach/wetland.

- Evaluate whether to pull levees back away from channels instead of following the status quo of "rebuild in place."

- In EWN, give consideration to adding Threatened and Endangered Speciesrelated features to increase project benefits.

- Actively store in, or mine from, confined dredged material placement facilities for use in Flood and Storm Damage Reduction emergency efforts.

Education and Training

- Culture Shift

- Acceptance and promotion of RSM and EWN approaches by Senior Leadership are a must to ingrain these concepts into practice across the Corps.

- At a minimum, the Corps must adopt a mind-set of ocean disposal only as a last option. Even slight improvements to small projects will be a step in the right direction.

- Education

○ Educating multi-disciplinary Corps personnel and stakeholders about the big picture is important. We must market the concepts to socialize, inform, and gain acceptance of RSM and EWN to attain greater participation and cooperation.

- Short- and long-term benefits arising from RSM and EWN projects need to be better defined and communicated internally and externally.

- Training

- Develop cross-training and exchange programs to assist in promoting RSM and EWN.

- Formalize Corps training for: RSM and EWN permitting, integrating RSM and EWN principles into Project Management Plans, general outreach and communication, and formulating cooperative agreements with resource agencies. 


\section{Question 2}

What gaps in science, technology, engineering, or organizational practice should be addressed to advance RSM and EWN across Corps mission areas? How do we advance RSM and EWN within the Navigation O\&M Program in particular?

Science

- With stakeholder-accepted data. Suggest using their research as a base to improve acceptability when possible, or using joint research funding and management.

- With additional and lengthier monitoring and improved sharing of biological monitoring data.

- By reporting effects of turbidity of biota (especially effects to semi-motile invertebrates and submerged aquatic vegetation).

- By utilizing currents and sediment transport for nourishment activities.

- Through mixed-grain dredged materials-sediment sorting and settling.

- By utilizing data on non-steady-state natural dynamics for planning with respect to functionality, resiliency, and sustainability.

Technology

- By developing a mechanism (similar to a questionnaire) for researching all the tools and data that are currently available in the "Corps Cloud" that would be applicable to a particular project or circumstance.

- Through modification of P2, to encourage the use of RSM and EWN. Add items to resources drop-boxes to help inform planning and evaluation on EWN/RSM and recommend $\mathrm{R} \& \mathrm{D}, \mathrm{S} \& \mathrm{~T}$ products that are applicable in performing these tasks.

- By creating a Corps-wide project database with at least the minimum information, searchable by location, project name, or district; access to historical data would be a huge bonus.

- By creating a Corps share space to match up project $R \& D$ needs with $R \& D$ project needs.

- By providing a clearing house to evaluate proposed technologies against existing or indevelopment efforts; by reducing duplication of effort.

- By synthesizing data in such a way so that complete data is accessible in one place.

Engineering

- By finding ways to keep sediment in system but reducing the infilling of channels.

- By utilizing deep-draft channel maintenance equipment (new-Post-Panamax).

- By designing guidance for EWN and RSM based on bio-physical understanding.

- By designing economical sediment separation equipment/methodology.

- By designing guidance for reservoir sediment management.

Organizational Practice

- By establishing an RSM/EWN Community of Practice for group learning and collaboration pushing forward and for nationwide utilization as a knowledge resource. 
- By launching a cultural change to proactively encourage RSM and EWN as possible alternatives, not unlikely wasted efforts. By injecting flexibility into the Navigation O\&M business line.

- Through improved consistency for evaluating EWN-oriented project benefits for both mitigation and determining credit for benefits achieved.

- Through an increase in the use of regional and systems-approach planning, for both logistics and economics.

- By utilizing "without project condition" to provide comparisons against projects which may have questionable resiliency or sustainability.

- Through systematic education to the field to advertise access to ERDC tools, technologies, and expert capabilities.

- By organizing and coordinating the many on-going (and sometimes - apparently similar or parallel) efforts to improve awareness and use of existing information.

Additionally, by allowing benefit from what has been learned and developed elsewhere to better tell the story of how we can use sediment as a resource or use it to achieve other EWN work.

- By dedicating funding for Quality Assurance and Control

- Through more early-stage, multi-agency collaboration on identifying potential project purposes, funding sources, and brainstorming alternatives. By including academia and industry personnel.

- By improving functional diversity on PDTs, by being inclusive.

- By increased awareness that social issues seem to be underrepresented in discussions. Social aspects should be included more explicitly if they are an equal pillar of EWN (or even of secondary importance).

- By encouraging a system-wide view; for example, by getting our Ops, Hydrology and Hydraulics, Planning, and other personnel together periodically to step back and reevaluate the big picture concepts and context.

- By developing an RSM Permit that can operate on a regional scale; this tool could reduce the number of permits needed for general RSM projects frequently undertaken for multiple regions within a district.

- By lending Office of Counsel and Contracting more flexibility in adaptive management of contracts and legal.

\section{Question 3}

How should we be communicating and collaborating with others to take full advantage of RSM and EWN opportunities?

Internally

- By developing an RSM and EWN joint Community of Practice - by merging Beneficial Use/Regional Sediment Management/Engineering with Nature into a more cohesive message.

- By having HQ-level and Division-level "champions" of RSM and EWN.

$\circ$ By increasing discussion in the middle-management levels to trickle down to the field level. 
- Workshops

- A strong support is needed to reduce funding and assumed policy impediments.

○ By coordinating bi-annual or annual workshops to promote the exchange of lessons learned and new ideas.

- By separating workshops into inland and coastal topics to increase relevance of idea exchange.

o By inviting more environmental business line experts.

- By providing a platform or baseline presentation for workshop attendees to take back to their home District for presentation to peers.

- By advertising RSM and EWN tools - by promoting the EWN geospatial viewer for idea research and outreach potential.

- By creating an email sign-up list to receive ERDC announcements of new tools/tech/studies. Those who sign up need to be sure to include POCs.

- The Corps needs smaller demo projects to provide information, start a "buzz," and develop the science and engineering.

- If a region has a great EWN project: Highlight it as "Project of the Month" on a widely viewed website like the HQ USACE website and monthly EWN/RSM email newsletters.

- By hosting training opportunities that are technical and practical and by ensuring they clearly identify the holistic, national benefits of RSM and EWN.

Externally

- Better outreach is needed; constant contact with resource agencies and regular stakeholders (not just immediate, need-based contact) is necessary.

- By having a diversified media strategy (social media and face-to-face) to reach a diverse group; we should do more to utilize Facebook, Twitter, YouTube, Web 2.0, etc. Tapping into the social media markets is a great way to reach students and the younger generations. Conversely, for older generations, face-to-face interactions are most profitable. We want to communicate with people and provide/receive instant feedback. Sending a nice, one-page flyer is better than sending a tech note; we need to share stories, not just facts and data.

- By using varying means to collaborate. Use alternate meeting locations and keep the atmosphere casual and comfortable to facilitate frank conversations and break down formality-supported barriers.

- During collaborations, be understanding/sympathetic to each other's situation/responsibilities/positions.

- By providing incentives for contractors to submit EWN proposals.

- By communicating to others about how EWN and RSM activities can help them; by developing a sediment-needs, "match-making" methodology.

- By communicating with the upper- and middle-management of partner agencies (e.g., NOAA, EPA) directly to try and gain their approval and endorsement of these ideas.

- By advertising and marketing - when we have a successful project - we need to erect a sign next to the project; by using promotional tools like T-shirts and cups that will get people to ask questions.

- By posting workshop results and presentations online for access by a much broader audience into the future. 
- By developing an EWN/RSM dictionary/glossary. (We have lots of different words and terms that will be unfamiliar to diverse stakeholder groups.)

- By utilizing communications strategies and knowledge transfer methods that appeal to all learning styles and that present data and concepts in simplified forms for communicating with non-scientists/engineers.

- By holding workshops that include divisions, districts, regulatory agencies, stakeholders, contractors, academia, etc. These should be regionally based and should last just one or two days to present and discuss concepts and relevant policies. Perhaps we could arrange a one-day information brief around other well-attended conferences/events.

- By holding annual "no decision" meetings - information only. By staying focused on being inclusive. There may be existing opportunities to partner with industry and local organizations that are yet untapped only because of a lack of awareness.

- By sharing information and stories of our successes on regional issues and topics of interest with the press (and possibly using a YouTube video series) to help popularize knowledge of USACE's involvement with RSM and EWN ideas. By providing links through an EWN/RSM website so we could easily and quickly share with partners and stakeholders to get them up to speed and capture their attention.

\section{Common Trends}

There were a number of common, noticeable trends in the comments that were voiced from all six groups. Frequent themes representing take-home messages from the breakout group discussions included:

- Communication - The most prominent theme throughout the breakout session discussions was the need for improved communication internally and externally. The view was that while high-level communication regarding RSM and EWN within the USACE is ongoing, communication between high, middle, and field-level areas was lacking within the USACE and with resource agencies. The groups suggested, in various ways, that the USACE needs a focused yet diverse communication strategy.

- Data Sharing and Capabilities Knowledge - There were many responses that addressed the need for greater sharing of data, especially monitoring data that could be utilized as "convincing" science for coordination with resource agencies. In addition, many attendees expressed a need for an easier way to determine what data currently exists and what technological and methodological capabilities the USACE retains for use.

- Funding and Policy - Many attendees expressed the opinion that for RSM and EWN to flourish there needs to be a change from the status quo regarding collaboration between business lines. The majority point was that current funding and policy structures are restricting the achievement of significant gains in the areas of RSM and EWN.

- Permitting - Alterations to the permitting process and/or offering topical training of regulatory personnel on RSM and EWN concepts was frequently suggested as a way to increase the ease of pursuing RSM and EWN projects. 
- Education and Training - There was a significant want by attendees for more education and training on RSM and EWN for USACE personnel and resource agency, NGO, and industry persons. Two popular suggestions in this area included dividing learning opportunities into inland and coastal classes and learning more about the "nuts and bolts" of implementing RSM and EWN.

WORKSHOP FEEDBACK: Prior to adjournment, participants were asked to provide feedback as to how the workshop could be improved for the future. The feedback included the following suggestions:

- Consider incorporating a field trip.

- Strive harder to invite non-USACE representatives.

- Due to the wide range of projects under its auspices that effectively demonstrate RSM and EWN, participants suggested that the Galveston District serve as next workshop host.

- Consider concurrent sessions where invitees vote on topics, thereby including them in the agenda decision-making process.

- Incorporate a side session for brief training about tools, models, etc.

- Invite contractors to introduce new technology.

ADDITIONAL INFORMATION: This technical note was prepared by Cynthia J. Banks, Research Biologist, and by Jennifer M. Gerhardt Smith, Research Biologist, Environmental Laboratory, USACE Engineer Research and Development Center. The study was conducted as an activity of the USACE EWN Initiative. For information on EWN, please consult www.engineeringwithnature.org or http://el.erdc.usace.army.mil/ewn. You may also contact the USACE EWN lead, Dr. Todd Bridges, at Todd.S.Bridges@usace.army.mil. For more information on RSM, please consult http://rsm.usace.army.mil/ or contact the RSM Program Manager, Linda Lillycrop, at Linda.S.Lillycrop@usace.army.mil. This technical note should be cited as follows:

Banks, C.J., and J.M. Smith. 2014. USACE Regional sediment management and Engineering With Nature 2012 workshop summary. EWN Technical Notes Series. ERDC TN-EWN-14-1, Vicksburg, MS: U.S. Army Engineer Research and Development Center. www.engineeringwithnature.org or http://el.erdc.usace. army.mil/ewn

NOTE: The contents of this technical note are not to be used for advertising, publication, or promotional purposes. Citation of trade names does not constitute an official endorsement or approval of the use of such products. 